\title{
An Overview of the Feasibility of Achieving Level 2 Building Information Modeling by 2016 in the UK
}

\author{
Abdulkadir Ganah and Godfaurd A. John \\ The Grenfell-Baines School of Architecture, Construction and Environment, University of Central Lancashire, Preston PR1 2HE, \\ $U K$
}

\begin{abstract}
The aim of this study is to investigate the current status and feasibility of achieving Level 2 BIM (building information modeling) usage that is to be made mandatory by the UK government on its projects by the year 2016. This study assesses the level at which organizational and practitioner knowledge of BIM is currently positioned. The UK government, being the largest public stakeholder client, has realized the benefits and advantages of BIM when used in procuring projects across their lifecycle in the built environment. A critical review of the BIM literature was carried out and the evidence base was created in relation to government targets for 2016. At the current stage, Level 2 BIM adoption is achievable by 2016 for large construction firms but not for SMEs (small medium enterprise). Also, from evidence in this study, the technology needs to be properly tailored to meet SME variables if Level 2 status is to be achieved for the entire industry.
\end{abstract}

Key words: Adoption, BIM, construction, levels.

\section{Introduction}

The construction industry sector is highly diverse, consisting of a range of discrete subsectors with an output of around $£ 107$ billion to the UK economy in 2010 and employing approximately 2.5 million workers. It is also a key element to the achievement of UK climate change targets [1]. The sector has undergone noticeable changes over the last six decades, which have led to considerable pressure from its member-organizations to respond swiftly and appropriately to their requirements. The need to change was well recognized in pivotal publications, including the 1994 Latham Report and 1998 Egan Report, which criticized the construction industry and acknowledged it as inefficient relative to other industries, especially manufacturing. Furthermore, the reports claimed that the sector is highly fragmented, with poor levels of

Corresponding author: Abdulkadir Ganah, Ph.D., research fields: building information modeling, buildability, ICT (information and communication technology) in construction, computer visualization, health and safety in construction, intelligent buildings, sustainability, skills development and training, and end users' involvement in design. E-mail: aganah@uclan.ac.uk. profitability, and slow to adopt technology and change in management and process. The recommendations that arose from issues identified in most of the reports and public commissions sponsored by government have been implemented in some areas, most notably the way that the UK government buys its projects. Presently, most are procured through the PPP (public private partnership), e.g., the private finance initiative, that enhances the working patterns of practitioners within the construction industry and augments the way the government does business. Through this procurement route, the UK government is able to offload most of the risk associated with such public projects, while at the same time, meeting the needs of local clients with their limited funding. Since usage of the new procurement route began, several projects have been completed successfully. However, one of the disadvantages with this approach is that practitioners on PPP contract projects are loosely integrated when it comes to their processes and procedures [2]. Another downside is that most practitioners and their organizations want to protect their IP (intellectual property), but at the same time, present a single front to 
the client stakeholder, that is, the UK government. In this regard, issues of cost escalation, time overruns, other project risks and lean management are evident in most reports coming out [3]. Against such a background, the UK government has realized that BIM will reduce negative viewpoints about these areas and bring about tight integration and coupling amongst firms operating within the industry.

Building information modeling and building information model are terms that are often used interchangeably, reflecting BIM's growth and the advantage it brings to the expanding needs of the construction industry. Expectations about BIM's implementation and usage vary across disciplines in the built environment. Most designers and consultants view BIM as an extension to CAD (computer aided design) and expect it to support integrated visualization and navigation, which is comparable to the CAD software that they are familiar with and some other parametric software currently in use. Contractors, project managers, and facilities managers, on the other hand, expect BIM to be a more intelligent DMS (document management system), which is a repository they can extract data from in time sequence, and such extracted data will mirror issues of cash flow modeling, simulation analysis, and risk scenario planning, as well as health and safety issues. As practitioner expectations of BIM are evidently different, so too is the stakeholder's expectation. In this regard, the UK government, being the largest public stakeholder client, realized the benefits and advantages of BIM when used in procuring projects across their lifecycle in the built environment. Usage and adoption of BIM in all UK government projects with a Level 2 BIM status is mandatory by 2016. Will this target be achievable?

Although the mandate is there for full 3D collaboration at this stage, which will translate into a substantial cost reduction of approximately 20\%, the UK government regulations did not prescribe how BIM Level 2 usage would be achieved by practitioners' organizations and their supply chain within the built environment. Hence, it is left to practitioners and stakeholders to come up with their own solutions to meet the government's minimum requirements. In this regard, this study investigates how the strategic, technical and operational requirements of BIM management are presently managed. It also examines how BIM education for practitioners is being undertaken in most tertiary institutions. The systematic literature review starts from 2011, when the government issued the mandate for BIM's theoretical approach, usage and practical implementation. The rest of the paper is divided into the following sections: the methodology used in the overall research; the BIM evolution; issues investigated with regard to BIM for practical implementation of Level 2 BIM; discussions; and then finally piecing together the various strands in the conclusions.

\section{BIM Innovation}

Innovation is a process through which new ideas, objects, and practices are created, developed or reinvented, and which are new for the unit of adoption [4-6]. Organizations adopt a range of different types of innovation to achieve service improvements, which are also true for organizations operating in the built environment. New services are offered to new and existing users, and internal changes are made to the operating system in an organization, to technical and administrative processes, and to intra- and inter-organizational relationships [7, 8]. Because public organizations (i.e., the UK government) may innovate in search of legitimacy and not fully adopt an innovation, implementation has to occur $[9,10]$ to ensure that improvements can be forthcoming.

There are different types of innovation, amongst which are evolutionary innovations: They involve delivering a new service to existing users. Process innovations, on the other hand, affect management and organization. They change relationships amongst organizational members and affect rules, roles, 
procedures, structures, communication and exchange among organizational members, and between the environment and organizational members. Therefore, they are concerned with how services are rendered [8, 11-13].

Organizational innovations are those that occur in structure, strategy and administrative processes [7]. In this study, they include improvements in an organization's practices and the introduction of new organizational structures [14-16]. Organizational innovations are thus concerned with their primary work activity and changes in the social system.

Technological innovations are associated with changes in physical equipment, techniques and organizational systems. Examples of technological innovations in public organizations would include information technology, hardware (physical equipment) and software (organizational systems).

Ancillary innovations are identified by Damanpour [7] and are differentiated from other innovations because they are concerned with working across boundaries with other service providers, users or other public agencies. Thus, their successful implementation is reliant upon others.

Generally, BIM innovation is a digital model of a building in which information about a project is structured in such a way that it can be shared, although there are different definitions of BIM depending on whose perspective is taken. For these definitions, we can refer to the following publications: NBIMS-US (National BIM Standard-US) [17], RIBA (Royal Institute of British Architects) [18], Penttila [19] and Succar [20]. BIM is a new innovation that is pervasive both in technology and in work processes affecting intra- and inter-organizational activities.

It is widely believed that BIM will help with integrating processes throughout the entire lifecycle of a construction project [21]. Even though the BIM concept has existed since the 1970 s, it is only over the last five years that building owners have become aware that BIM has the potential to make the design, construction and operation of buildings much more streamlined and efficient [22]. Moreover, BIM is increasingly gaining ground as a means of developing buildings and infrastructure that are problem free and a better fit for the purpose with high efficiency. BIM innovation and development can be expressed, as shown in Fig. 1. However, there are a number of barriers to the implementation of BIM in the UK construction industry, including but not limited to:

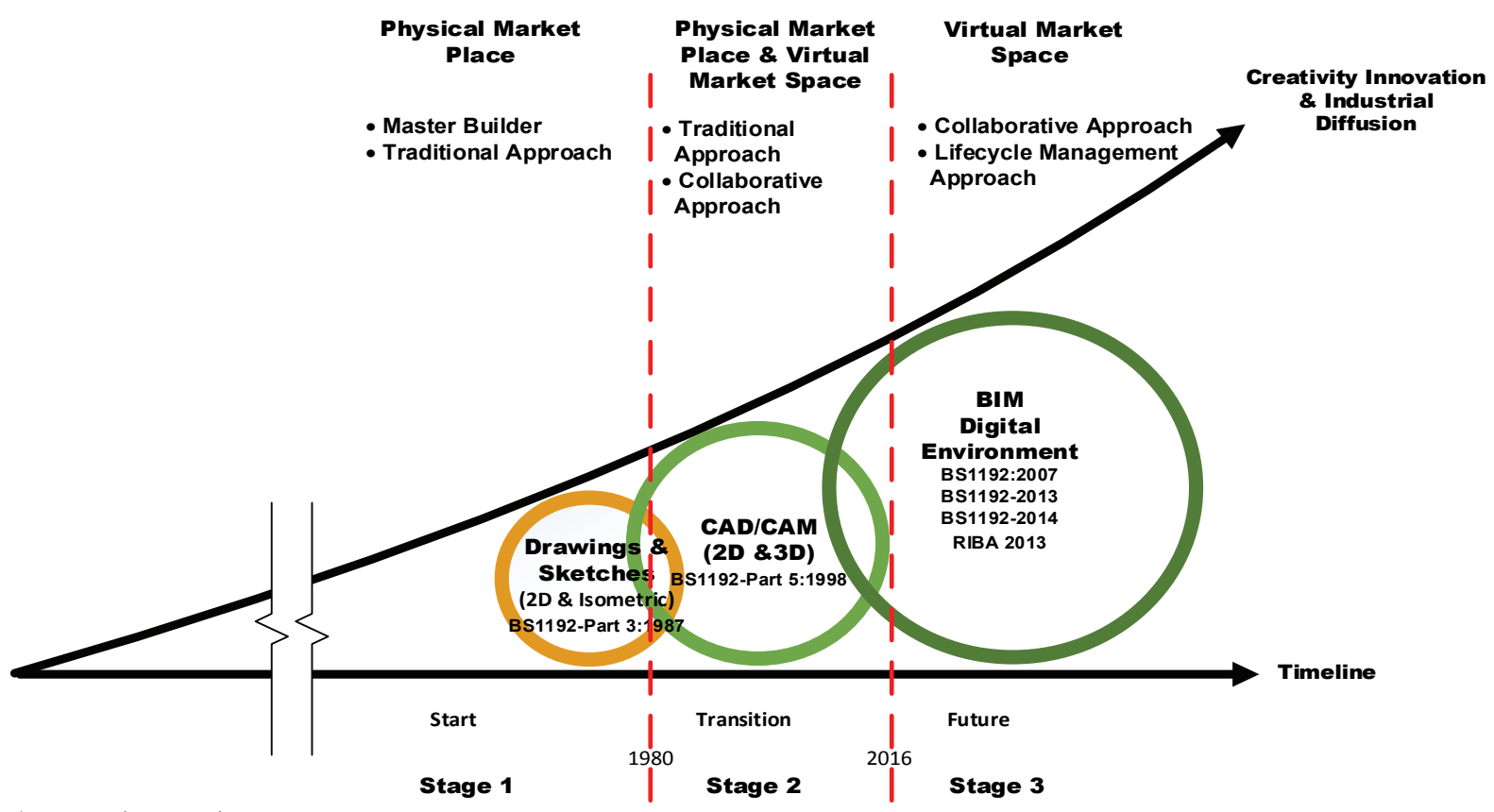

Fig. 1 BIM innovation and development. 
- a resistance to change culture within construction industry professionals, especially those at the top management level, and getting these people to understand the potential and realize the value of BIM over conventional design and management tools [3, 23];

- training employees on BIM, which require all project stakeholders to use and train their employees on BIM [24];

- availability of the infrastructure required for BIM, including high-end hardware and networking facilities to run BIM applications and tools efficiently, and a components' library which requires manufacturers to produce 3D models for their components in BIM-compatible format [25];

- understanding the importance of collaboration, integration and interoperability between all stakeholders;

- lack of clear understanding on the part of construction lawyers and insurers of the responsibilities of different stakeholders [22];

- absence of a common language for data exchange.

All of the above can only be overcome through collaboration, including government, public and private sectors, industry bodies, software developers and researchers. The industry needs to become less fragmented and adversarial, and there is a strong requirement to encourage better integration from all stakeholders involved in a construction project. Janney [25] and Connaughton [26] indicate that due to the additional number or parties involved in managing and maintaining the BIM model, there could be more multi-party agreements rather than the traditional two-party agreements with which the construction industry is more familiar.

In the UK, a BIM maturity framework has been developed to ensure clear delivery of the levels of competence expected, the supporting standards and guidelines, their relationship to each other and how they can be applied to projects and contracts in the construction industry.

The UK government requires a fully collaborative
BIM Level 2 (with all project information, documentation and data in an electronic format) as a minimum by 2016 on all public projects [23]. Level 2 comes third in a four-tiered system, as listed below [27]:

(1) Level 0: BIM is the use of 2D CAD files for production of design, as-built and maintenance information. A majority of design practices and facilities' organizations have used this process for many years. The important point to be noted until Level $1 \mathrm{BIM}$ is reached is that common standards and processes (i.e., in CAD) were merely a $2 \mathrm{D}$ repository in each independent organization that are not shared exclusively by all organizations in the lifecycle of the facility being produced. Hence, the use of CAD failed to gain traction as the common platform shared by all when CAD was developed;

(2) Level 1 consists of the utilization of both 2D and $3 \mathrm{D}$ information in projects. The use of 3D tools beyond this stage has commonly been limited to large infrastructure projects in which 3D aids the understanding of clients and financiers that do not possess the necessary expertise in a $2 \mathrm{D}$ alternative. However, because of its added advantage of visualization, other disciplines (i.e., mechanical and electrical contractors) have also adopted it. This is a significant step forward towards sustainability issues of waste minimization and inefficiencies in current AEC (architecture, engineering and construction) industries. In terms of process, Level 1 requires management process to be alongside design process;

(3) Level 2 requires the production of 3D information models from the integrated project team, which fosters collaborative working and a relational contracting approach. It is not expected that the contractual or insurance issues currently used by the industry will change, once the current deficiencies within contractual issues are properly dealt with. Hence, the outputs required at each stage need improved requirement definition, with clarity from the lead designer at each stage, in order to co-ordinate the 
design as it progresses;

(4) Level 3 consists of a single online project $n \mathrm{D}$ model (where $n$ represents the number of functional characteristics considered in the BIM environment, e.g., 4D (inclusive of time), 5D (inclusive of time and cost) and 6D (inclusive of time, cost and facilities management). The challenge of Level 3D and beyond is not simply about collaborative working, but rather the use and application of BIM in the $n \mathrm{D}$ dimension, in which other professional discipline will make use of the information within the BIM platform as a rich source of knowledge for future projects. Since management of projects, as well as design, as-built and maintenance information, is all in one repository, the value of such information to public sector projects will be immeasurable with reference to the procurement of future projects. Issues of risk, health and safety, environmental analysis and value management can also be the starting platform for understanding future scenarios for similar projects.

From the above, Smith [28] argues that many projects are on different parts of their BIM journey. Most of the UK is still at Level 1 (2D/3D CAD) with regards to BIM, while some firms were seeing the benefits of Level 2 (managed 3D CAD utilizing 4D or 5D), thus improving productivity and time management with their projects. He also notes that a firm's adoption of new BIM systems is dependent on industry/client push/pull. In May 2011, Government Construction Strategy [23] was published, with the ultimate aim of reducing the cost of government construction projects by $15 \% \sim 20 \%$ by the end of April 2014. This strategy aims to implement Level 2 BIM throughout all UK practices by the year 2016, in all projects worth $£ 5,000,000$ and over [23].

\section{Methodology}

The first step was to use a traditional literature review method to understand the evolution and development of BIM technology up to 2011, when the government mandate was issued for BIM usage on government public projects. This method was used to ascertain the rise, usage, adoption and diffusion of BIM technology in the construction industry. From 2011 onwards, the research approach has been a systematic review of the available literature to understand the industrial variables that have changed or their lack since 2011.

A systematic review is an overview of primary studies that contains an explicit statement of objectives, materials and methods, and which has been conducted according to an explicit and reproducible methodology. The purpose of a systematic review is to provide the best available evidence on the likely outcomes of various actions. And if the evidence is unavailable, to highlight areas where further original research is required, the advantages of a systematic review are that [29]:

- Its methods limit bias and the rejection of data, thereby providing the information required;

- Since conclusions are drawn from the process used, the reliability is assured when compared to other literature review methods that do not contain this amount of analytical rigor;

- It encourages the assimilation of relatively large amounts of information by practitioners, researchers and professionals.

The guidelines for this study's systematic review have been adapted from methodologies developed and established over more than two decades in the health services sector [29] and informed by developments in other sectors such as social sciences and education [30].

The question then to be asked is: What evidence exists that there is an increase in activities involving the usage and uptake of BIM by organizations within the built environment on government projects?

The research designed and used to find an answer to the above-mentioned question is an eclectic approach, embracing both quantitative and qualitative research documents. High-quality systematic reviews were adopted and the following steps were carried out [29]: 
- Identify all relevant published and unpublished evidence;

- Select studies or reports for inclusion;

- Assess the quality of each study and reports;

- Synthesize the findings from individual studies and reports in an unbiased way;

- Interpret the findings and present a balanced and impartial summary of the findings, with due consideration of any flaws in the evidence.

The sources used in this study came from the following, in order of relative importance for academic rigor:

- Databases - those highly favored by the built environment academic body (Table 1), as well as engineering academics. This database contains a rich source of original published research on BIM;

- Government and affiliate bodies' policy and other documents - the government documents are the underpinning articles that drive the uptake of BIM within the UK and, as such, will contain fundamental rationale for encouraging the uptake of BIM. The affiliate bodies are inclusive of the various professionals institutions within the built environment (i.e., BSI (British Standards Institute), RICS (Royal Institution of Chartered Surveyors), CIOB (Chartered Institute of Building) and RIBA);

- Conference proceeding-conferences and their proceedings are a major channel of communication among experts in any field. They are initial budding research forum from various researchers throughout the world that also contain research resources of articles from on-going research. The three chosen proceedings are ARCOM (Association of Researchers in Construction Management), CIB (International Council for Building) and COBRA (Constraint-Based Reconstruction and Analysis). The last five years of publication are investigated for reliable articles;

- BIM task groups-this is a group formed to provide help and support in delivering the objectives of Government Construction Strategy and has the requirement to strengthen the public sector's capability for BIM implementation, with the aim that all central government departments will be adopting, as a minimum and collaborative Level 2 BIM by 2016;

- SNS (social networking sites) — these are virtual communities where users can create individual public profiles, interact with real-life friends and meet other people based on shared interests. They are seen as a "global consumer phenomenon" with an exponential rise in usage within the last few years [31]. The social networking site that is subject specific, though informal, also contains another rich resource that will make use of the way practitioners perceive their work in the future. LinkedIn is chosen as the social network in which a BIM forum is presently heavily used by practitioners;

- Other "gray" literature, like magazines and the worldwide web, was investigated but few outputs were included in this investigation.

The search criterion used within the systemic review process is that all documents should start in and around the time the government strategy for full implementation was issued (2011). This will, in effect, follow the trend of developments about BIM as it progresses from this point onwards, underpinned and supported by the UK government. Anything before this

Table 1 Selected databases used in the systematic review.

\begin{tabular}{llcr}
\hline Database name & Meta-search terms used & Number of articles found & Number of article chosen \\
\hline Science Direct & BIM, adoption, barriers & 124 & 14 \\
Emeralds Engineering & BIM, adoption, barriers & 19 & 2 \\
Sage & BIM, adoption, barriers & 6 & 1 \\
ARCOM & BIM, adoption, barriers & 9 & 1 \\
COBRA & BIM, adoption, barriers & 36 & 1 \\
CIB W78 & BIM, adoption, barriers & 2 & 0 \\
\hline Total number of articles from the database & 194 & 19 \\
\hline
\end{tabular}


period will be taken as known from the traditional literature review.

The criteria for the selection of reviewed articles are as follows:

- Once the database was selected and the articles pertaining to these terms chosen, the first step was to use the meta-search terms (i.e., BIM, adoption and barriers, as well as BIM 2016);

- After that, articles with such terms were collated and a further, deeper search was used (e.g., achieving BIM 2016);

- These terms were used as document analysis terms to further investigate the evidence coming out within the industry;

- Note that in this study, author's H-index, nor a search by authors, was carried out.

The information that is relevant for the full implementation of BIM in 2016 is summarized in the next section.

\section{Findings}

The findings from this study are categorized into five areas:

(1) Practitioners and users of the technology: Designers and consulting practitioners are the predominant users of BIM currently. Contractors are lagging behind in the uptake of the technology. The literature is deficient in the usage of BIM amongst subcontractors even with specialist subcontractors, and it is rare or almost non-existent. There is no evidence within the industry of a planned strategic approach to the successful usage and implementation of BIM through the building's lifecycle. There were a few systematic approaches, but these were not followed up by practitioners in the way that the technical issues of BIM were being implemented, before the PAS (Publicly Available Specification) 1192-2013 protocol and BIM overlay of RIBA Plan of Work 2013 were developed. The task groups formed by different institutions (CIB, RICS, CIOB, RIBA, etc.) are not yet fully integrated to give a holistic understanding of the underlying long-term issues about integrated and collaborative working;

(2) BIM projects: There are presently a number of trial projects that the government has identified and commissioned for BIM usage. Of these, only one has been completed [32];

(3) Technology innovation: The improvement in software technology and interoperability for the BIM technical areas of implementation is moving in the right direction, with 4D (time), 5D (cost) and 6D (facilities management) integration being made possible through different software vendors. The development of BIM's technical aspects is not driven by any particular software "giant" and issues of interoperability are developing alongside open software systems;

(4) Education and learning: Universities and further education colleges are not significantly engaged in new modules addressing the usage of BIM by rolling out new courses to plug the knowledge gap about this technology in the near future. So far, despite some architecture schools having incorporated the usage of BIM software in their design studios, this relates only to the technology and is limited in what it can bring both to BIM's management issues and its related capabilities. Very few postgraduate courses have been identified so far as solely dedicated to BIM usage and practical implementation;

(5) BIM communication issues: There are not many articles within journals and conference proceedings that are effective in disseminating utilization of BIM throughout the product's life cycle. SNS discussing BIM is not sufficiently grounded in issues related to original research issues about BIM to make a meaningful contribution to the development of BIM Level 2 adoption by 2016.

From the documents examined so far, it is not clear from all the practitioners what is meant by achieving Level 2 BIM by 2016. Since the government strategy did not define a road map or steps by which to achieve this, it is rather difficult to address from a practitioner's perspective. 


\section{Discussions}

The industrial variables that have changed significantly since May 2011 are the following:

- There is now an RIBA Plan of Work 2013 with BIM overlay existing: This was not evident in the literature before 2011 that one can safely point to. This plan of work will underpin the way professional institutions and bodies plan their strategy in the usage of BIM holistically. The buy-in of these institutions is lending weight to shaping the way BIM adoption will occur, both strategically and managerially;

- There is now a new protocol for BIM usage (i.e., PAS1192-2) that underpins the British standard (i.e., BS1192-2007), in which uptake was low as it was thought to be geared towards the information industry in the first instance. Considering the fact that PAS was sponsored by the Construction Industrial Council, its sound organizational membership will improve the way BIM is procured and used. The introduction and appointment of the information manager within the PAS protocol is new and not fully spelt out in relation to the issues of communication and collaboration with the other organizations that will be involved in the project;

- Most professional bodies and institutions now have task groups that actively promote BIM within their rank and file, as well as hold seminars or workshops to educate their members through CPD (continuous professional development);

- Research in educational institutions has also increased, although it is not evident that there is a definite strategy for achieving meaningful results through a more strategic agenda rather than “firefighting” BIM issues as they develop;

- Most undergraduate courses in institutions now have modules that are BIM oriented, or aspects of BIM have been incorporated in existing modules, which will make outgoing graduates sensitive and active users of BIM technology;

- Very few institutions are rolling out postgraduate BIM courses;

- The surveys conducted by industrial groups, in particular NBS (National Building Specifications), from 2011 to date show that there is an increase in the adoption of BIM in the industry. However, this increase in adoption is mainly by large companies which have the resources to do so. SMEs (small and medium enterprises) are still lagging behind because of lack of resources and or management strategies.

From what is seen from the work carried out so far in this study, it is right to say that some tremendous efforts are being made towards the industry achieving full Level 2 collaborative 3D BIM implementation: However, not all practitioners or their organizations would have reached this level. The reasons for this is the fact that in construction, the issue of subcontracting is prevalent. These SMEs are actually not large firms, but have the highest of percentage concentration in the construction industry. Most of the large firms that get contracts from government are within sight of full collaboration, but not so for the medium and smaller firms. Again, it is evident that the concentration of large construction firms in the built environment comprises designers and consultants, and some very large contractors, too. Still, the majority of firms involved in construction implementation after design and consultation and design development are concentrated in the implementation stage.

\section{Conclusions}

The construction industry practitioners and stakeholders need an integrated platform to collaborate and enjoy an effective and efficient working environment, which is offered by BIM. This research shows that the industry is responding positively to this challenge. There is evidence that many organizations are using BIM for government-procured projects. However, large organizations within the lifecycle of the built environment are all at different levels of BIM development, Level 1 being the most dominant amongst organizations and practitioners. Some large organizations are at BIM Level 2. There is no evidence of any organization(s) operating at Level 3, except for 
the interface between Levels 2 and 3. Practitioners are becoming more knowledgeable through their institutions-run CPD programs, while contractors (i.e., large) are also informed through the relational procurement routes they are engaged in, forcing them to change and adapt to this new form of collaboration. Some universities are starting to adopt a multidisciplinary curriculum supported by BIM, but this needs to become the standard not the exception. The downside, though, is the fact that since every organization has some form of data presence in BIM, there is no evidence of a federated approach that will manage the legal sharing and usage of data, as each firm wants to protect its intellectual property rights. The main challenges for SMEs is the added cost (i.e., in training of personnel, software and related hardware), and consequent reduction in profit margins. For SMEs to buy in, there must be some government incentives (e.g., tax rebate/relief) that will motivate them in the direction of BIM adoption. However, it is paramount that the UK government continues to champion and sustain the push towards BIM adoption, with more projects achieving the goal of Level 2 collaborative working by 2016. This study is critical for the industry, as we are operating in a globalized world. Therefore, having a persistent data platform (i.e., BIM), which can be accessed anywhere in the world, will make the teething problems encountered during the implementation stage of BIM in the UK manageable to others.

\section{Acknowledgments}

The authors would like to thank and acknowledge the Grenfell-Baines School of Architecture, Construction and Environment, University of Central Lancashire for generous support and encouragement of this research.

\section{References}

[1] HM Government. 2012. Building Information Modeling. HM Government, UK.
[2] Ganah, A., and John, G. A. 2013. "Suitability of BIM for Enhancing Value on PPP Projects for the Benefit of the Public Sector." Presented at PPP International Conference 2013 Body of Knowledge, Preston, UK.

[3] Murray, M., and Langford, D. 2003. Construction Reports 1944-98. Oxford: Blackwell Publishing.

[4] Aiken, M., and Hage, J. 1971. "The Organic Organization and Innovation." Sociology 5 (1): 63-82.

[5] Kimberly, J., and Evanisko, M. 1981. "Organizational Innovation: The Influence of Individual, Organizational, and Contextual Factors on Hospital Adoption of Technological and Administrative Innovation." Academy of Management Journal 24 (4): 689-713.

[6] Rogers, E. M. 1995. Diffusion of Innovations. New York: Free Press.

[7] Damanpour, F. 1987. "The Adoption of Technological, Administrative, and Ancillary Innovations: Impact of Organizational Factors." Journal of Management 13 (4): 675-88.

[8] Edquist, L. H., and McKelvey, M. 2001. Innovation and Employment Process versus Product Innovation. Cheltenham: Edward Elgar.

[9] Boyne, G., Martin, S., and Walker, R. 2004. "Explicit Reforms, Implicit Theories and Public Service Improvement." Public Management Review 6 (2): 189-210.

[10] Damanpour, F., and Evan, W. 1984. "Organizational Innovation and Performance: The Problem of 'Organizational Lag'." Administrative Science Quarterly 29 (3): 392-409.

[11] Abernathy, W. J., and Utterback, J. M. 1978. "Patterns of Industrial Innovation.” Technology Review (June/July): 40-7.

[12] Damanpour, F., and Gopalarkrishnan, S. 2001. "The Dynamics of the Adoption of Product and Process Innovations in Organizations." Journal of Management Studies 38 (1): 45-65.

[13] Damanpour, F., Szabat, K. A., and Evan, W. M. 1989. "The Relationship between Types of Innovation and Organizational Performance." Journal of Management Studies 26 (4): 587-601.

[14] Borins, S. 1998. Innovating with Integrity: How Local Heroes Are Transforming American Government. Washington DC: Georgetown University Press.

[15] Light, P. C. 1998. Sustaining Innovation: Creating Non-profit and Government Organizations that Innovate Naturally. San Francisco: Jossey-Bass.

[16] Walker, R., Jeanes, E., and Rowlands, R. 2002. "Measuring Innovation-Applying the Literature-Based Innovation Output Indicator to Public Services." Public Administration 80 (1): 201-14. 
[17] National BIM Standard-US. 2007. United States: The National Building Information Model Standard, Version 1-Part 1. National BIM Standard-US.

[18] RIBA. 2012. BIM Overlay to RIBA Outline Plan of Work. London: RIBA Publishing.

[19] Penttila, H. 2006. "Describing the Changes in Architectural Information Technology to Understand Design Complexity and Free-Form Architectural Expression." Journal of Information Technology in Construction 11: 395-408.

[20] Succar, B. 2009. "Building Information Modelling Framework: A Research and Delivery Foundation for Industry Stakeholders.” Automation in Construction 18 (3): 357-75.

[21] Jung, Y., and Joo, M. 2011. "Building Information Modelling (BIM) Framework for Practical Implementation." Automation in Construction 20 (2): 126-33.

[22] Arayici, Y., Coates, P., Koskela, L., Kagioglou, M., Usher, C., and O'Reilly, K. 2011. "BIM Adoption and Implementation for Architectural Practices.” Structural Survey 29 (1): 7-25.

[23] Cabinet Office. 2011. Government Construction Strategy May 2011. UK: Cabinet Office.

[24] Khosrowshahi, F., and Arayici, Y. 2012. "Roadmap for Implementation of BIM in the UK Construction Industry." Engineering, Construction and Architectural Management 19 (6): 610-35.
[25] Janney, M. 2012. "Building Information Modelling ('BIM') - The Government Lays Down the Law!." Brachers. Accessed May 30, 2013. http://www.brachers.co.uk/news/item/building-informatio n-modelling-bim-the-government-lays-down-the-law.

[26] Connaughton, J. 2012. Getting the Most Out of BIM. A Guide for Clients. London: Davis Langdon and Aecom Company.

[27] BIM Task Group. 2011. BIM: Management for Value, Cost and Carbon Improvement Strategy, Paper for the Government Construction Client Group from the BIM Industry Working Group-March 2011. London: BIM Task Group.

[28] Smith, D. 2012. "How Does BIM Affect Quantity Surveyors and Project Managers.” Construction Journal 1: 8-10.

[29] Higgins, J., and Green, S. 2012. Cochrane Handbook for Systematic Reviews of Interven-tions. Version 5.1.0. USA: John Wiley \& Sons, Ltd.

[30] Gough, S. O., and Thomas, J. 2012. An Introduction to Systematic Reviews. London: Sage.

[31] Kuss, D., and Griffiths, M. 2011. “Addiction to Social Networks on the Internet: A Literature Review of Empirical Research.” International Journal of Environmental and Public Health 8: 3528-52.

[32] Cabinet Office. 2012. Government Construction: Construction Trial Projects July 2012. UK: Cabinet Office. 